\title{
A Guide to the Identification of Burins in Prehistoric Chipped Stone Assemblages
}

Jean M. Pitzer

Center for Archaeological Research

Follow this and additional works at: https://scholarworks.sfasu.edu/ita

Part of the American Material Culture Commons, Archaeological Anthropology Commons, Environmental Studies Commons, Other American Studies Commons, Other Arts and Humanities Commons, Other History of Art, Architecture, and Archaeology Commons, and the United States History Commons

Tell us how this article helped you.

This Article is brought to you for free and open access by the Center for Regional Heritage Research at SFA ScholarWorks. It has been accepted for inclusion in Index of Texas Archaeology: Open Access Gray Literature from the Lone Star State by an authorized editor of SFA ScholarWorks. For more information, please contact cdsscholarworks@sfasu.edu. 


\section{A Guide to the Identification of Burins in Prehistoric Chipped Stone Assemblages Creative Commons License (c) $($ ) $(9)$}

This work is licensed under a Creative Commons Attribution-NonCommercial 4.0 International License 
A GUIDE TO THE IDENTIFICATION OF BURINS IN

PREHISTORIC CHIPPED STONE ASSEMBLAGES

Jean M. Pitzer

Center for Archaeological Research The University of Texas at San Antonio Guidebooks in Archaeology, No. 1

1977

Second Printing 1979 


\section{PREFACE}

With this volume, the Center for Archaeological Research, The University of Texas at San Antonio is initiating a new publication series entitled Guidebooks in Archaeology. Like the present contribution authored by Jean M. Pitzer, Guidebooks are designed as basic references for anthropology and archaeology students, avocational archaeologists, and professional archaeologists. Many of the numbers in this new series will deal, for the most part, with archaeological topics relevant to Texas archaeology; others, like this first volume, will be broader in scope.

Forthcoming volumes will cover a wide range of subjects. These include a guide to plants and aboriginal plant use in south central Texas, a compendium of lithic tool forms found in south and central Texas, and a checklist of the fauna of present-day and prehistoric southern and central Texas.

Thomas R. Hester

Director

Center for Archaeologica1 Research 


\section{ACKNOWLEDGMENTS}

I am indebted to my husband, Kenneth S. Pitzer, for his assistance in innumerable ways, and for his patience in storing many boxes of debitage; to my sister, Mildred R. Glacken, for her assistance in collecting; to my neighbors in Toyon Cove--Mr. and Mrs. R. Ray Rowe, Mrs. Edna Arganbright, Mr. John A. Walters and Mrs. Virginia McMaster--for their loans and contribution of specimens; to Dr. Robert F. Heizer who nurtured my interest in burins; to Dr. Thomas R. Hester for his advice and encouragement; and to Mr. Colin I. Busby for much help. The illustrations were drawn by Judith Ogden. 
Burins are perhaps the most interesting and complex of a1l of the tools of prehistoric man and they continue to be objects of considerable interest to archaeologists. As Noone writes $(1950: 186)$, the burin "may be said to be the first specialized working tool of all man's artifacts." No other tool was made in such a variety of types, yet burins which are consistent in form and design are found in many different cultures. Burins were first recognized in Paleolithic assemblages in Europe as tools which had been made with great skil1 and precision for the performance of specific but multiple types of tasks--tasks which were soon identified (in Europe) by experiment and replication (Movius 1966, 1968). However, the emphasis in the study of burins soon shifted from the study of their function to that of classification of all the types and variations of types. More recently, burins have been found in widely separated sites in the New World. The number of sites has risen steadily as students have learned to recognize burins in an increasing number of lithic assemblages. This guidebook is written in the hope that it will assist students, particularly beginning students, to make that identification more easily, and also to encourage more replication and experimentation with burins, especially in relation to the contexts in which they are found in the New World.

To begin at the very beginning--the first thing for the student to do is to read books such as Burkitt (1963), Crabtree (1972), Bordaz (1970), 0akley (1964) and Tixier (1974). Most of these books can be found in paperback editions at bookstores, particularly university bookstores. From these, one can learn the elementary characteristics of the features which are left on a core when a blade has been detached. The characteristics of a plane of fracture on the ventral side of a blade should also be learned. 
Burkitt (1963:42) makes an excellent suggestion. He advises students to take a flint tool (or any piece of flint or obsidian which has had several flakes removed) and study it to determine the direction from which came the blows which detached the flakes. This is essential because the most obvious, important and diagnostic attribute of a burin is the burin facet. The burin facet is made when a small bladelet or spall is detached from the parent piece as described by Burkitt (1963:64) and Tixier (1974:9-14) and in order to be able to recognize it, one must know the direction from which the burin blow was struck. Other characteristics which one must learn to recognize are: negative bulb of percussion, positive bulb of percussion (or bulb of force), eraillure scar, fissure, concentric or compression rings, striking platform, and hinge fracture.

Next, learn to recognize what a "break" looks like (Fig. 1,i).* Breaks can be the result of an intentional or accidental "snap" and can be either slightly convex or slightly concave, but in both cases the "rolled" look and "lip" is exhibited as described below. Epstein (1963a:194) describes it we11:

The first step in burin identification is to distinguish between a broken edge and a burin facet. A break usually shows a slightly 'rolled' surface, and one edge of the break has a sharp lip or depression as a result of the two pieces hinging apart. . . A burin facet, however, has very sharp edges, and often a slightly concave surface. A negative bulb of percussion just below the striking platform is usually considered diagnostic of the burin technique because it indicates that a burin blow has been struck. The major problem in burin identification is not to distinguish between a burin facet and a break; it is, rather, to determine whether the facets result from intentional or accidental burin blows.

* The burins and other artifacts illustrated are part of a much larger collection of materials being analyzed and prepared for a forthcoming paper, "Toyon Cove, California--A Surface Site of the Westem Pluvial Lakes Tradition," by Jean M. Pitzer and Thomas R. Hester. 
Accidental burin blows, or impact burins, result when a spear point or a dart point strikes a hard surface and a spall is detached parallel to the length of the point along the lateral edge (Fig. I,c). To be able to distinguish between accidental and intentional burin blows can only come from experience. But if you find a projectile point which has what appears to be a perfect burin facet along a lateral edge and which does not have an opposing facet, or is not opposed by an edge prepared by retouch or truncation, and which does not have a well-defined working edge showing use wear, then you should assume it is an accidental and not a true burin.

Epstein (1963b:33) later conducted some experiments and demonstrated that neither a negative bulb of percussion nor a hinge fracture is necessarizy a diagnostic feature of the burin technique (see also Giddings 1964; Pitzer, Hester and Heizer 1974). Also, as Bourlon (Pitzer 1977:27-36) points out, working edges of some burins have been so modified by use that the "diagnostic" negative bulbs of percussion have been worn away, or have been sharpened in such a way that they have been remade into different types of burins, obscuring the original negative bulb of percussion or the original hinge fracture. But the greater percentage of burins which are not too worn do have both a negative bulb of percussion and/or a hinge fracture on the facet, and these features greatly facilitate positive identification. Read Epstein (1963a) for a more detailed discussion concerning methods of distinguishing between accidental and intentional burin facets.

The next step is to study papers by the early researchers who constructed the first typologies of burins. Of these, Bourlon (1911) is the most important and instructive, and is basic to any further study of burins. His paper, written in French, has been published in an English translation by Pitzer (1977) 
along with Burkitt's (1920) and Noone's (1934) classifications. Be sure to read the section in Bourlon on the sharpening of burins, as it will give you a better understanding of the working edge of a burin. Study the illustrations carefully. Note how the burin facets are arranged in order to form the working edge.

Next, go to a museum, preferably an anthropological museum. Almost all museums, particularly university museuns, have an exhibit of the lithic technology of prehistoric people. Often museums have authentic plastic reproductions of burins available at the sales counter.* A study of these is invaluable in order to get the feel of a burin as a tool. The greatest handicap for the student who wishes to learn about burins is a lack of sufficient specimens of the various types to study and to handle. If one is able to handle a burin, one gains a sense of the purpose of its design and construction and of its possible function, just as one does with any genuine tool. Perhaps the anthropology department at the university will have a case or two displaying tools; usually at least one or two burins are included in such an exhibit. While you study the burins, do not be distracted by the terminology which you have just studied--concentrate. on the working edge and its shape. Identify the burin facets. Try to envision what tasks it would be suitable for the tool to perform. Then go home and study again the illustrations in Bourlon (Pitzer 1977), Burkitt (1963:64-69), Bordaz (1970) and Tixier (1974).

Here we must discuss one point that frequently confuses beginning students--

* These reproductions may also be ordered from the producer, the Denver Museum of Natural History, City Park, Denver, Colorado 82005. They are copies of Paleolithic burins made on prismatic blades and are from European collections. It is very unfortunate that reproductions of burins from North American PaleoIndian sites such as the dated burins from the Levi Site in Texas (Alexander 1963) are not available. 
the fact that the terms "graver" and "burin" are sometimes used by different authors to define the same tool. European authors often refer to burins as gravers, while American authors consider a graver to be "a stone implement generally made by pressure flaking and intentionally designed to have a functional point or points" (Crabtree 1972:68). The quotation from Burkitt (1963:42), below, illustrates this. Also, Burkitt (1963:64-69) uses the term "graver" instead of "burin" throughout his discussion of tool families.

When you are confident of being able to recognize burin facets, you are ready to identify burins--following the traditional process of trial and error. Every error will result in additional information, and every identification of a true burin will assist you to gain greater expertise. After you have found your first true burin the differences between pseudo-burins will become much more apparent to you. Once you have learned to recognize facets on a piece you will soon be able to identify true burins and to sort out quickly other flakes which you feel were not made with a similar sense of purpose. Always carry a magnifying glass with you. With it you can discern a negative bulb of percussion, concentric rings, or a hinge fracture which will help to confirm a burin facet. The magnifying glass can also assist you in examining the working edge of a burin or possible burin. Sometimes the degree of wear or use on a supposed working edge can be the decisive factor in deciding whether you have found a true burin. When judging the amount of use wear on the working edge, consideration must be given to the fact that natural "wear" due to weathering and abrasion often can be mistaken for use wear. Although most burins fall easily into the typical categories and classifications, there are others which defy a rigid classification system (Fig. 4,b; Fig. 5,a,c), yet have all the necessary attributes of true burins. However, to focus our attention on those burins which conform to the most classical types, and 
therefore can be conveniently classified, and to ignore the more aberrant forms of burins would result in the loss of a great deal of valuable information. This is the crux of the difficulty posed by rigid classification systems. Movius et al. (1968) have proposed a new system of classification by attributes which is very promising, and which they feel will help in the understanding of "burins as burins." Unfortunately, however, one must be an expert in burin identification before this system can be used.

An observation of Burkitt's about the difficulties in using classification systems is pertinent here (1963:64-65):

Though prehistoric man certainly seems from time to time to have desired to make different shaped gravers [i.e., burins] in different ways, gradations between these so-called types certainly do occur, and hard and fast divisions are all very well when the selected specimens exhibited in museum series are considered, but in the field intermediate varieties are also found.

Further, Noone (1934:91) says:

- . on account of the great divergence of form of some of the types, one is prompted to ask whether we have not been led into stretching the term graver, or burin, to cover some implements which are in reality not true or simple burins, but allied tools. Certainly the extreme forms of the burin merge almost beyond distinction into other classes of instruments.

These quotations illustrate the advantage of approaching the study of burins as tools which have the necessary attributes of burins, rather than as "type fossils" as Movius et al. (1968:22) put it. Here your study of burin facets as components of a viable working edge of a burin and as contributing factors to the useability of the burin as a tool will be an advantage to you in deciding whether to classify a tool as a burin or as a different type of tool.

One complication is that sometimes the burin blow as a technique is used 
in ways which result in a tool which is not functional as a burin. For example, the technique may be used to shape the tip or edge of a projectile point (Fig. 1 , b; cf. Epstein 1963a; Tuohy 1969), or to prepare a tool for hafting, or to blunt the sharp edges of a tool in order to make it easier and more comfortable to hold (Semenov 1964; Coles and Higgs 1969:66). The latter state:

Al though it has genera11y been assumed that all flakes with such [burin] facets are burins .... recent study of a few isolated specimens has demonstrated that in these cases the burin facet was in fact used to blunt the edge and the working surface of the tool was elsewhere on the edge. Tools with naturally sharp edges may therefore have been used as knives or scrapers, and the burin facet served the same purpose as blunting retouch. The importance of these regrettably few observations can hardly be over-emphasized for the typological studies of relevant industries and their functional significance (Fig. 3,i).

This writer has found, at least in the Toyon Cove assemblage, that if burins are present, the burin technique is pervasive, although perhaps not obviously so to the untrained eye, and is frequently used in many ways other than for the manufacture of true burins. The burin technique is, of course, almost identical to that of removing a blade from a core (Pitzer, Hester and Heizer 1974), which is why it is frequently referred to as the 'blade and burin tradition," and why, if burins are present in an assemblage, prismatic blades frequently are present also. In this case blades removed from a core are usually struck with greater force, resulting in a complete detachment from the core; while if a burin is intended, the blow will be struck with lesser force, resulting in a hinge fracture.

If you encounter a burin facet on a tool about which you are uncertain whether it has all the necessary attributes of a burin, study the use wear scars on the piece, and you can usually determine if it is a true burin or not. The writer has found gravers and awls, the points of which were delineated on 
one or both sides by burin blows in order to isolate the graver or awl point (Fig. 1,e; Fig. 3,f,g). These tools, of course, were classified as gravers or awls, and not as burins, since the burin facets were not part of the essential working edges of the tools.

Burins are made on a wide variety of flakes, blades (Fig. $3, h, j$ ), heavy bifaces, cores, or broken projectile points (Fig. 1,a,b,d,g,h; Fig. $2 j$ ) as well as on other tools such as scrapers or awls (Heizer and Kelley 1961; Epstein 1963a; Tuohy 1969). Occasionally one finds a combination tool such as a scraper on one end and a burin on the other.

One can find great variability in the range of sizes and the quality of materials and workmanship in burins. It has been this writer's experience that some burins seem to have been made carelessly, intended perhaps for a single use and then discarded, while others are made with extraordinary skill and care--with sharp edges retouched or ground so that the use of the tool would be comfortable, and the working edge sharpened and resharpened. Sizes can range from delicate tools of less than an inch (Fig. 4,a) to large rugged ones of six inches or more, designed, probably, for very rough work (Fig. $5, \mathrm{~b}, \mathrm{c}$ ).

The study of burins cannot be separated from that of the study of burin spalls--the bladelet or microblade which is detached from the parent piece by the "burin blow" or "coup-de-burin." The first burin spall to be detached, the primary spall, is triangular in cross section. When the working edge needs to be sharpened, the secondary spall is detached, and this and all subsequent spalls are approximately rectangular in cross section. Primary burin spalls are very similar to the crested blade or the "lame a crete," the first blade to be detached from a polyhedral core. But the difference between the two can be detected by careful study. Burin spalls will more frequently end in hinge 
fractures. Frequently when one is sorting out flakes and artifacts, one finds a burin spall before a burin is found. This is a valuable clue that burins may be present in the assemblage. Obviously, just as burins come in all sizes, so do burin spalls (Fig. 3,a-e). Occasionally one finds that the burin spall itself has been made into a small burin. Burin spalls can also give important information on the technique used to manufacture different types of burins, and all of the specialists have used them to study the burin technique. (See Bourlon in Pitzer 1977; Noone 1954; Giddings 1956, 1964; Epstein 1963b; Tixier 1974). The illustrations of the various types of burin spalls in Tixier (1974:11-12) are particularly helpful. This topic deserves a great deal more attention and research.

When you think you have found a burin, make a drawing of it for your own record, and also make a detailed record of where it was found; then show it to an archaeologist. He can confirm whether it is a true burin, and, if not, you will learn why not. The presence of burins is part of the recoverable knowledge of the site and should be included in any report. If you are assisting in a supervised archaeological excavation, you will have plenty of material to examine, and also help with identification.

A further step should also be suggested, and that is to do some imaginative experimenting concerning the function of burins. Although some, functions and uses of prehistoric burins have been known with certainty since their first recognition in Europe as distinct tools, most of the emphasis in the study of burins has not been focused on function, but, rather, on typology and classification, to the point that an unfortunate amount of mystique has obscured our understanding of burins as tools. Inevitably and obviously, our understanding of the functions of burins will remain static if the focus in the study of burins 
remains on classification rather than on experimentation. Since most of the experimentation which established the function and uses of burins has been done within the context of European assemblages, with the exception of those of Arctic origin (see Giddings 1956, 1964), it is very probable that much additional information can be gained by experimenting with replications of burins found within the contexts of American Paleo-Indian and Archaic sites. For accounts of the few experiments concerning the functions of burins, see Movius (1968), Pitzer (1977), Hester and Heizer (19.73), Clark and Thompson (1954), Epstein (1963a) and Spencer (1974).

If you have a talent for flint-knapping, try to make some simple burins. The more sophisticated and complicated burins probably can be made only by experienced knappers, as these frequently are true works of art. Never experiment with a prehistoric or protohistoric burin. To do so would damage the evidence and information that the study of the working edge can give, especially when viewed under a microscope, and possibly could result in breaking off the working edge. If, after the burin has been examined for use wear and records made of such, if present, and after a drawing has been made of it, yout might use the burin very lightly on a pad of paper to discover the pattern it makes. Using it on bone or wood would destroy the evidence on the working edge rapidly. Additionally, a burin which one finds in the field perhaps will have the working edge dulled by the original use as well as by abrasion and weathering, and so might not give an accurate indication of its original pattern as a tool. Try to replicate a burin which you have found. A replicated burin with fresh working edge can be compared with the prehistoric burin to see if one can gain new information on the type of use to which the working edge of the original tool was subjected. Also, by replicating original burins and experi- 
menting with them with their fresh working edges, one might be able to test some long held assumptions which may or may not be correct. For example, see the following quotation from Burkitt (1963:67):

Ordinary Gravers. When the blade or flake is thin, one burin facet on each side of the working edge is sufficient to make an effective tool (bec-de-flute) . . ., where the blade or flake is thick two or more facets parallel to one another and in the same plane may be necessary either on one side only (single facetted) or on both sides (double facetted) of the working edge. Naturalzy this working edge will no longer be as even as when the tool was formed by the intersection of two graver facets only, as it is almost impossible to make the various facets absolutely parallel and in the same plane. But though the working edge may appear slightly irregular when examined, the student should have little difficulty in assigning the graver in question to the screwdriver rather than to the gouge class. (Italics added.)

This author has found that those burins with two or more parallel facets in the same plane often make a pattern of two or more parallel lines. It may be that the intent in fabricating a single or double facetted bec-de-flute burin was to make an even and regular working edge, and was constructed in that form solely to give strength to the working edge. It is also possible that the irregular working edge formed by the multiple facets described above by Burkitt was the desired result in order to construct a tool which would make parallel lines, and which would facilitate the execution of a cross-hatching or similar design in a wood or bone ornament or other artifact. It is possible, also, that an uneven working edge on a burin would assist in a gouging or planing action. Answers to these questions can be determined only by experimentation.

It is appropriate here to suggest that new approaches be made by first discerning what types of patterns are made on a surface by different types of burins, and then deciding what function it would be logical for each type to perform. The next step would be to go back to the museums and look at displays 
which show artifacts collected in the area where burins have been found. See if you can discern evidence of the use of the types of burins found in that area on such things as engraved or incised bone and wood, leather items and basketry. Epstein (1960:96) makes the interesting suggestion that the burins belonging to the Pecos River phase would be valuable and useful in splitting reeds for basketry, as well as for woodworking. The large burins (Fig. 5,b and c) seemingly would be useful to flatten and process the tule rushes which the Pomos used to weave into skirts for women and leggings for men, as well as for woven mats. The fragile burins in Fig. 4,a and b, may have been used for medical purposes, and surely the consistent forms of the beaked series (Fig. 4, C-i) should suggest some rational theories for their use or uses. As Giddings has stated (1964:211), "Burin implies a group of instruments made by a common technique; it does not always imply equivalence of function." The possibilities are numerous.

Finally, you should go back and re-read Bourlon's, Burkitt's and Noone's classification systems. You will want to become familiar with at least one of these classifications (Bourlon's is the one most frequently used) in order to write about and describe your finds so that other workers in the field can conduct comparative studies and benefit by your experience. 


\section{EXPLANATION OF ILLUSTRATIONS}

(Note: All of the items illustrated are obsidian. The burins are described not only by the formation of the working edge and of the facets, but also by the construction of the whole tool, as the author feels that both are related to the possible functions of the burins. Technical terms have been kept to a minimum.)

Figure 1:

a) Burin made on a point. Two small burin facets on one lateral edge at the base are opposed by one large facet. There is a negative bulb of percussion on the large facet and pronounced concentric rings.

b) Burin made on a lanceolate point. The base has been truncated and used as a platform from which to strike a single burin blow. There is moderate wear on the working edge. A small facet has been made at the end of the point at the center of the dorsal ridge. This facet may have been used to shape the tip of the point.

c) A good example of an accidental or "impact" burin, and therefore not a true burin. The tip of the point has been broken off on impact, and the force of the blow also detached a spall along the lateral edge of the point.

d) A burin made on a large broken wide-stemmed point, one shoulder of which has been removed by trimming. A large thinning flake has been removed in the center of each face of the point. A small flake has been broken off at the working edge at right angles to the burin facets, and is a more recent fracture.

e) This should probably be classed as an awl or drill rather than as a burin, although the point was delineated on each side by a burin blow. The facets do not meet at the tip and are not part of the working edge. There is minute retouch along the sides of one "facet."

f) A long narrow burin on a small blade. The distal end was snapped and a facet created in such a way that there is a small bec at the working edge. The bec has been retouched and shows use wear. The facet ends in a hinge fracture.

g) Two opposing facets meet at the working edge of this burin made on another broken point. The working edge shows heavy wear. A section of the tip has been snapped off and then been sharpened by retouch so that there is a small bec on the point. This burin may have been designed for hafting.

h) This is a burin made on a mid-section of a lanceolate point and has a diamond cross section. Both ends have been snapped off, one facet made on the lateral edge, and one immediately adjacent on the face of the 
point. The working edge shows heavy wear and several small flakes have been removed on one facet--either by sharpening or by use wear. Both facets end in pronounced hinge fractures.

i) This burin has been made on a piece of black tabular obsidian with some red obsidian striations on one face. It is essentially rectangular in form and all four sides were first shaped by deliberate breaks; then the break at the top was used as a striking platform to detach a single burin spal1. The break at the top was snapped from front to back as shown in the illustration, and the one containing the burin facet from left to right. Both are good examples of a "break." The break on the lateral edge opposite to the burin facet has curved to meet the base. The base has an unusually convex break.

j) A simple burin with two opposing facets (bec-de-flute) made on a biface.

Figure 2:

a) This is an extremely sophisticated burin--a well planned and beautifully executed design. It is made on either a broken point or a biface of flawless obsidian which has a smooth greasy feel. Both sides have been carefully flaked. The burin was used so that the base is the large break made along one lateral edge. This break is markedly concave. There are two facets parallel to one another at a slight angle and to the right of center of the lateral edge opposite to the break. There is one facet to the left of center. The result is a working edge composed of a series of facets along the curved edge at the top of the concave break. The small triangle at the center top is not believed to be a facet. All three facets end in pronounced hinge fractures and show a great deal of wear at the working edge. This burin was examined under a 20-75x microscope by Dr. Thomas R. Hester, who stated that the area of greatest wear is underneath the center tip, directly under the small triangle, where heavy crushing shows. It also appeared that the burin was used with a pushing motion and that the tip was embedded in the material. The working edge is beveled in the direction of the push.

b) This burin is made from the same quality of obsidian as (a) and has the same smooth greasy feel. It is made on a biface which has been carefully flaked and shaped. It is a bec-de-flute in design, with two parallel facets along one lateral edge, and one facet on the opposite edge. The working edge of the single facet has been trimmed or sharpened by retouch. Al1 three facets exhibit strong hinge fractures.

c) Another bec-de-flute with a single large facet opposed by two paralle1 facets. It appears that originally there was only one facet on the side which now has two facets, and that the second, smaller facet was made as a device to sharpen the original facet. The working edge is concave and shows considerable wear. 
Figure 2:

d) A bec-de-flute. One large facet ending in a hinge fracture is opposed by two parallel facets which curve the full length of the piece. The facet to the left has had its working edge broken, while that to the right has been sharpened by two minute facets struck from the working edge.

e) A double burin, with a single blow burin made on a break at both ends. The original flake was first snapped at both ends with breaks, then careful flaking done on both faces. The break at the top of the drawing is shown and is concave. The lip or hinge at the top rear of the break is also shown. A large flake was removed along the lateral edge just to the right of the facet. Then a burin spall was hit in such a way that a small bec was created, as illustrated. There is use wear on both. the working edge of the burin and the point of the bec. On the opposite end a burin spall was detached, using the break at the base as a striking platform. This facet extended the full length of the piece.

f) A large burin made of a fine quality of obsidian without impurities or flaws. It is made on a flake which has been broken on the left side and the base. Then it was shaped by retouch along the entire curved length of the lateral edge to the right, as well as the under side at the left (not shown). A large notch was made on the left lateral side, and three parallel spalls were removed, two of which end at the notch.

g) Burin with a single large facet opposed by two larger facets, the working edges of which have been sharpened by the removal of two small facets.

h) A burin made on a large flake. The top was removed by a break snapped at an oblique angle. Another flake was removed to the right of the lateral edge. Then two burin facets were struck. The working edge has been sharpened by retouch.

i) A burin somewhat similar to Fig. 2,e, in that the purpose appears to have been to create a burin with a small bec. It is made on a thick flake, snapped at the top and shaped by retouch at the base. The long narrow facet at the left was made by striking off a spa11, using the tip of the bec as a striking platform. This made a very sharp working edge on the bec. The two other facets help to isolate the bec, but it would be difficult to use them as part of the working edge.

j) A burin made on a mid-section of a heavy lanceolate point with a diamond cross section. The top consists of a burin facet, and the base has been trimmed by lateral flaking, as has the lateral edge opposite the burin facets. One burin spall was removed along a lateral edge of the point and was later sharpened by a second spall removal from the same spot. The result is again a small bec with a facet running along its face. 
Figure 2:

k) A burin-scraper combination made from a thick flake which is essentially square in outline. There is a burin facet on each of two sides of the square; the one at the left ends in a hinge fracture. The remaining two sides of the square are retouched and show use as a scraper. The corner at the upper right has been trimmed by retouch on the right hand end of the burin facet in order to create a small bec.

Figure 3:

a-e) A series of burin spal1s. All are primary spalls with a triangular cross section, and (c), (d), and (e) have a typical twist. The base of (d) shows that it broke with a strong hinge fracture, and (b) has been retouched along one edge and along the tip subsequent to removal.

f) An awl made on a strongly curved flake. A ridge has been made down the center of the dorsal side by the removal of a flake on the left and the removal of a spall by the burin technique on the right. Most of the wear on the piece is on the lateral sides of the extended point.

g) A graver, with the working point made in much the same style as $(3, f)$ above. The burin facet which helped to form the point does not contribute to the working edge. The point has been trimmed by retouch.

h) A burin made on a blade. A remant of the striking platform is at the base. One long facet has been made along a lateral edge of the blade. At the broken distal end, one spall has been struck off at an angle, and another has been struck parallel to the latter on the dorsal face. A third facet was made subsequently to sharpen the latter.

i) A large scraper made on a piece of tabular obsidian. The cortex remains on both faces. The base has been snapped off. The lateral edge on the right side was shaped by a large spall removed by the burin technique. A large flaw in the obsidian was revealed by the burin blow. The burin facet does not reach the working edge of the scraper, and the flaw may have forced the redesigning of the tool. The working edge was later shaped by a series of flakes struck from the top and lateral edges. The large burin "facet" serves to make the scraper feel comfortable in the hand, and it may have been struck for that purpose. A small facet was made at the lower left hand corner apparently for the same reason. There is no use wear on that edge.

j) Another fine burin made on a blade with much the same basic design as $(3, h)$. The striking platform is at the base of the drawing. The small drawing shows the striking platform and the preparation of the platform for the removal of the blade. The dorsal side of the blade shows large laterally flaked scars. The top of the illustration shows that the blade was truncated by a burin blow, and a second facet was made parallel to it on the dorsal face at an angle. The working edge was completed by the removal of a burin spall on the top left lateral edge of the blade. The working edge shows crushing and wear. 
Figure 4:

a) A very delicate burin made on the tip of a small broken point; the point has a diamond cross section. One burin facet has been struck at the top left-hand lateral edge. This facet carries across the point to the opposite side, ending in a hinge fracture. It is opposed by another facet on the opposite side, and this, in turn, was sharpened or thinned by a facet which almost obscures the first. The result is a long thin extension which is less than $1 \mathrm{~mm}$ thick at the tip. The thin screwdriver-shaped working edge shows use.

b) A very oddly shaped burin, made apparently with the purpose (like 4,a) of achieving a broad facet with as thin a working edge as possible. A curved flake was utilized and flaked so that a broad thin area makes an extension. One broad facet forms one side of the burin. The opposite side is formed by four distinct facets, and the working edge is approximately $1 \mathrm{~mm}$ thick. Small flakes have been detached by use wear on the working edge.

c) An oblique, straight angle burin on a flake made by one facet which ends in a hinge fracture and is opposed by a retouched edge. It has a slight "parrot beak" profile.

d) See below.

e) A double burin on a flake. There is a small burin facet at the top left corner and the working edge at the base of the flake is formed by two opposing facets. The curvature of the flake gives this burin a slightly beaked profile.

f) A burin with a working edge which shows a great deal of wear. One facet along one edge of the flake has had a small oblique flake removed by use. Another facet opposed the first, and is almost completely obscured by use wear and sharpening by retouch.

$\mathrm{d}, \mathrm{g}, \mathrm{h}, \mathrm{i}$ ) A series of beaked burins. (d) and ( $h$ ) have been made on blades; $(g)$ and $(i)$ on thick flakes. All approach a form which can best be described as beaked or busque. All seem to be designed to be held firmly in the hand so that the index finger could support the beak, and so that carefully controlled strong pressure could be used on an object.

(d) Made on a small blade. The burin spall which truncates the beaked tip was hit off very near the striking platform of the blade. One large burin spall extends down the lateral edge of the blade and has expanded into the ventral face, ending in a hinge fracture. The area on this large facet just under the working edge has been retouched extensively. 
Figure 4:

g) Made on a heavy flake. There are two parallel facets across the top. One large facet was struck along one side of the beak and then extensively retouched by coarse flaking. Sharp edges of the piece have been removed by retouch.

h) Made on a blade. The dorsal ridge has been removed for two-thirds the length of the tool. A very small section of the working edge at the proximal end of the blade has been broken off. The largest facet was made on one lateral edge. Two small facets were struck parallel to it. One broad expanding facet has been struck on the ventral face.

i) Burin made on a heavy amorphous flake. Two small facets have been struck at $90^{\circ}$ angles to each other on the beaked sections. The working edge has the pentagonal cross section shown. The original tip of the beak probably was broken off, and was subsequently retouched along one facet. The present working edge shows use wear.

Figure 5:

a) An interesting burin. Four facets have been struck on this heavy flake. Three are large, wide ones which serve to delineate the point at the top. Two of the three facets exhibit hinge fractures. A small fourth. facet was struck along a ridge which intersects two other facets, creating the working edge. The tip of the burin shows use wear, and the ridge opposite to the small burin facet shows retouch.

b) A very heavy-duty burin. One large burin spall was struck off along the lateral side to the right. A second facet was made at an oblique angle, meeting the first facet. The working edge thus constructed is very worn and abraded, and there is retouch along the oblique edge of the second facet. The base end of the burin has hinged off an it is impossible to tell whether or not the apparent facet there was part of another working edge. The lateral edge opposite the large spall has been carefully retouched.

c) This large burin is interesting as it seems to have been constructed in much the same design as (a), only on a larger scale. One large burin spall was struck off on the right edge of this heavy biface. On the opposite side another spall was struck at such an angle that it expands on to the opposite face. Then a smaller facet was made at the intersection of the two large facets. The result is an elevated working edge, curved at such an angle that a great deal of force can be applied along the flat "screwdriver" edge of the working edge. Small flakes have been detached by use along one edge of the smallest facet and along the "notch" adjacent to it. All of the rough edges of the burin have been removed by retouch, and one face shows light trimming flakes. 

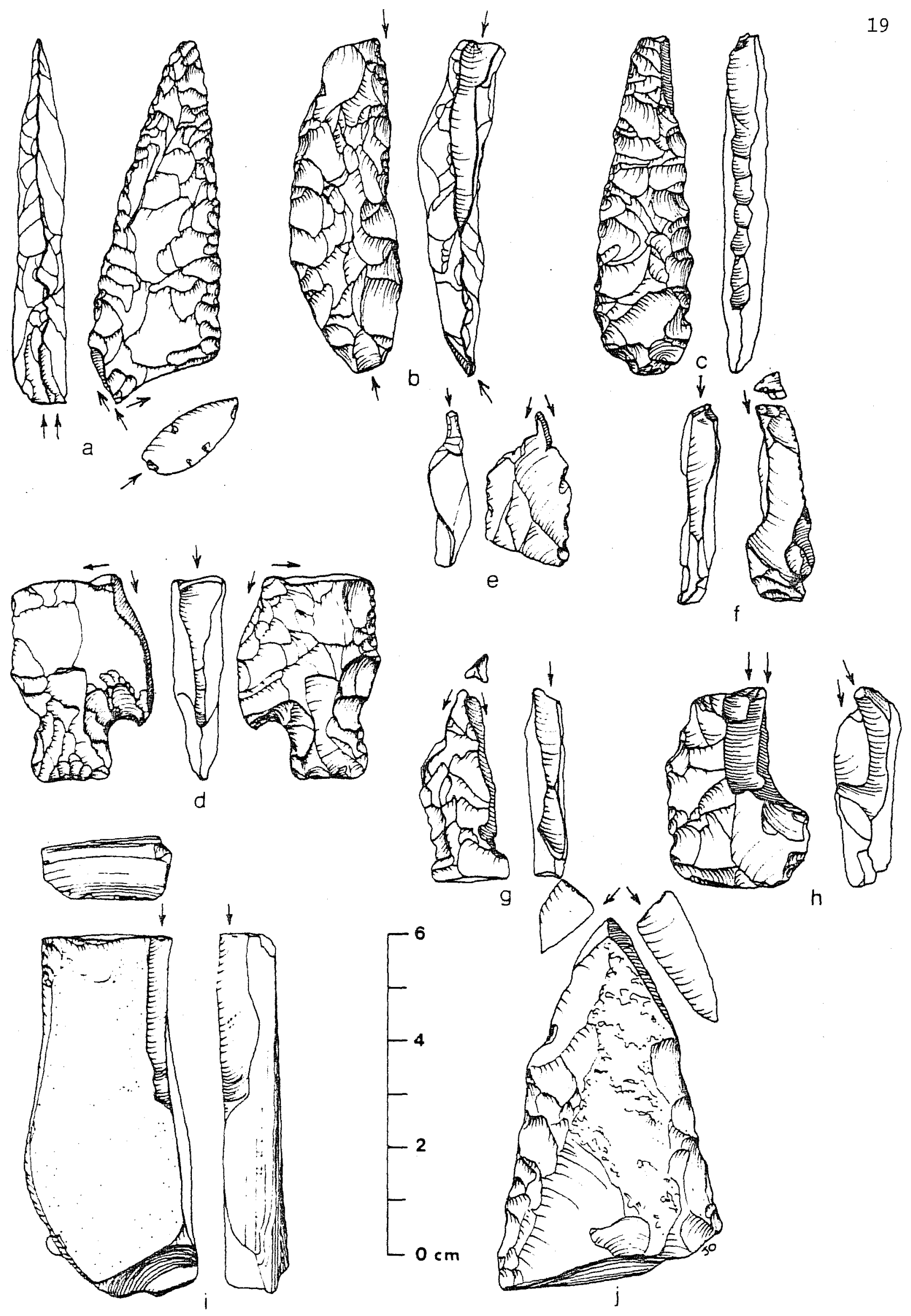

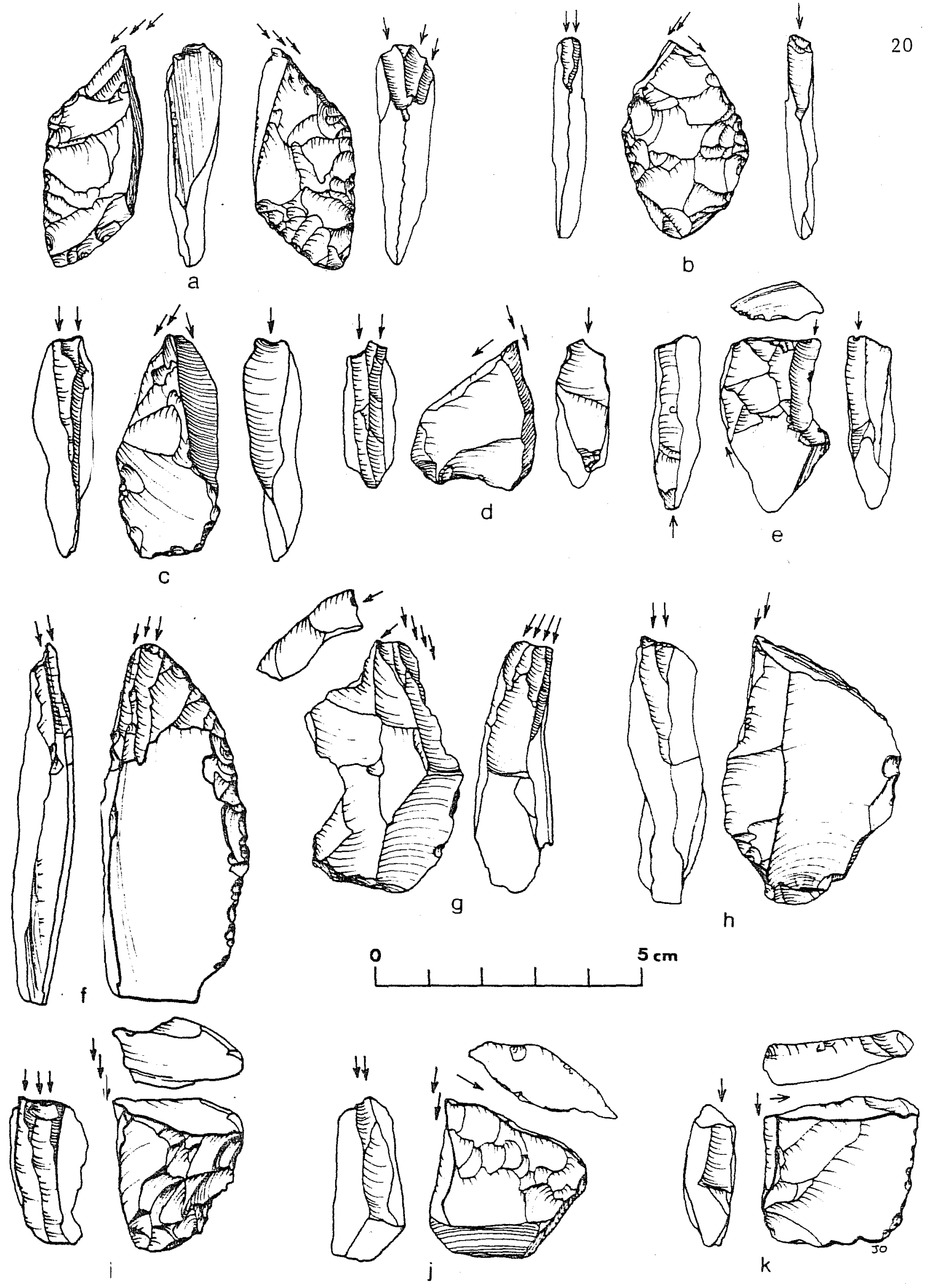

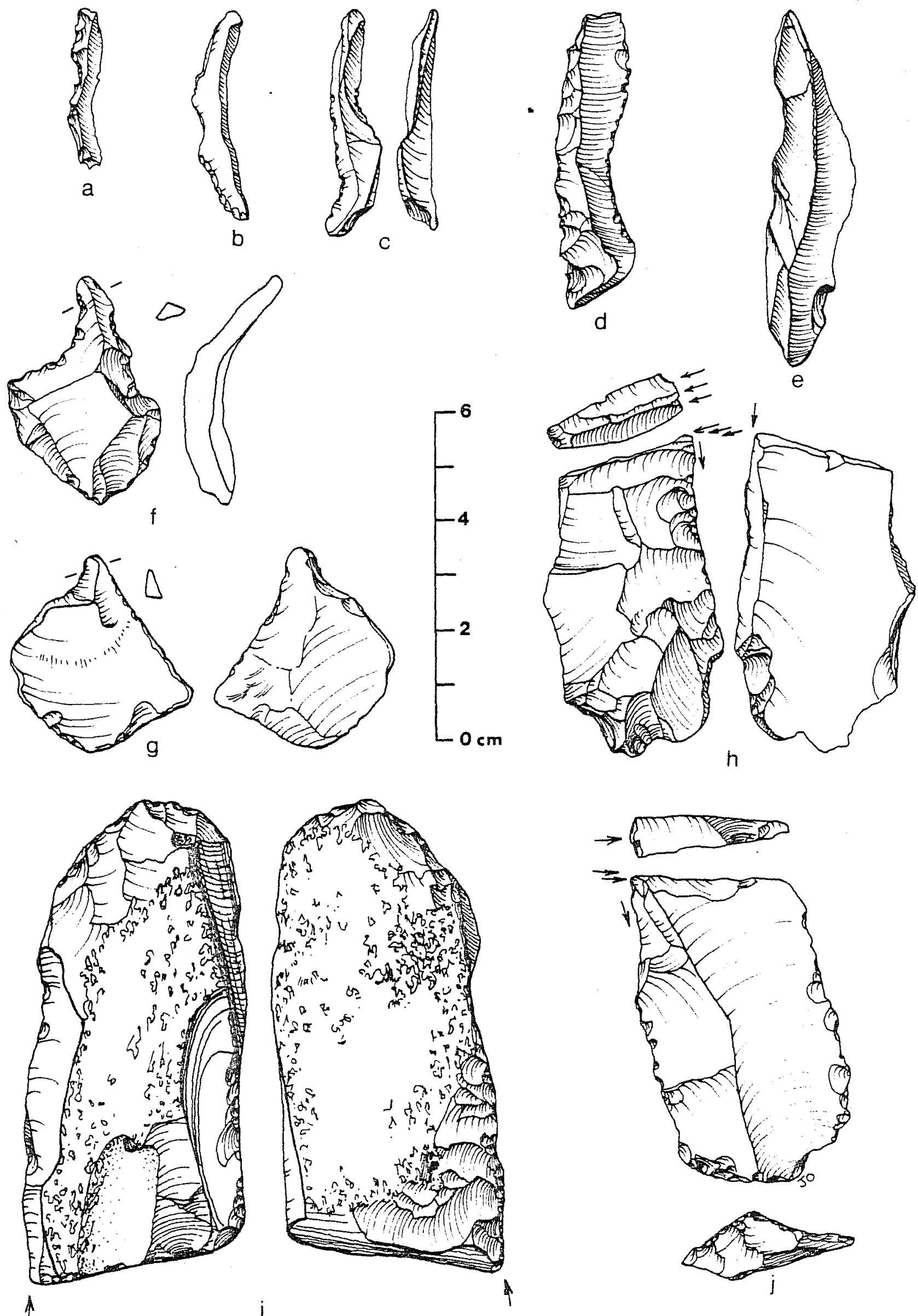

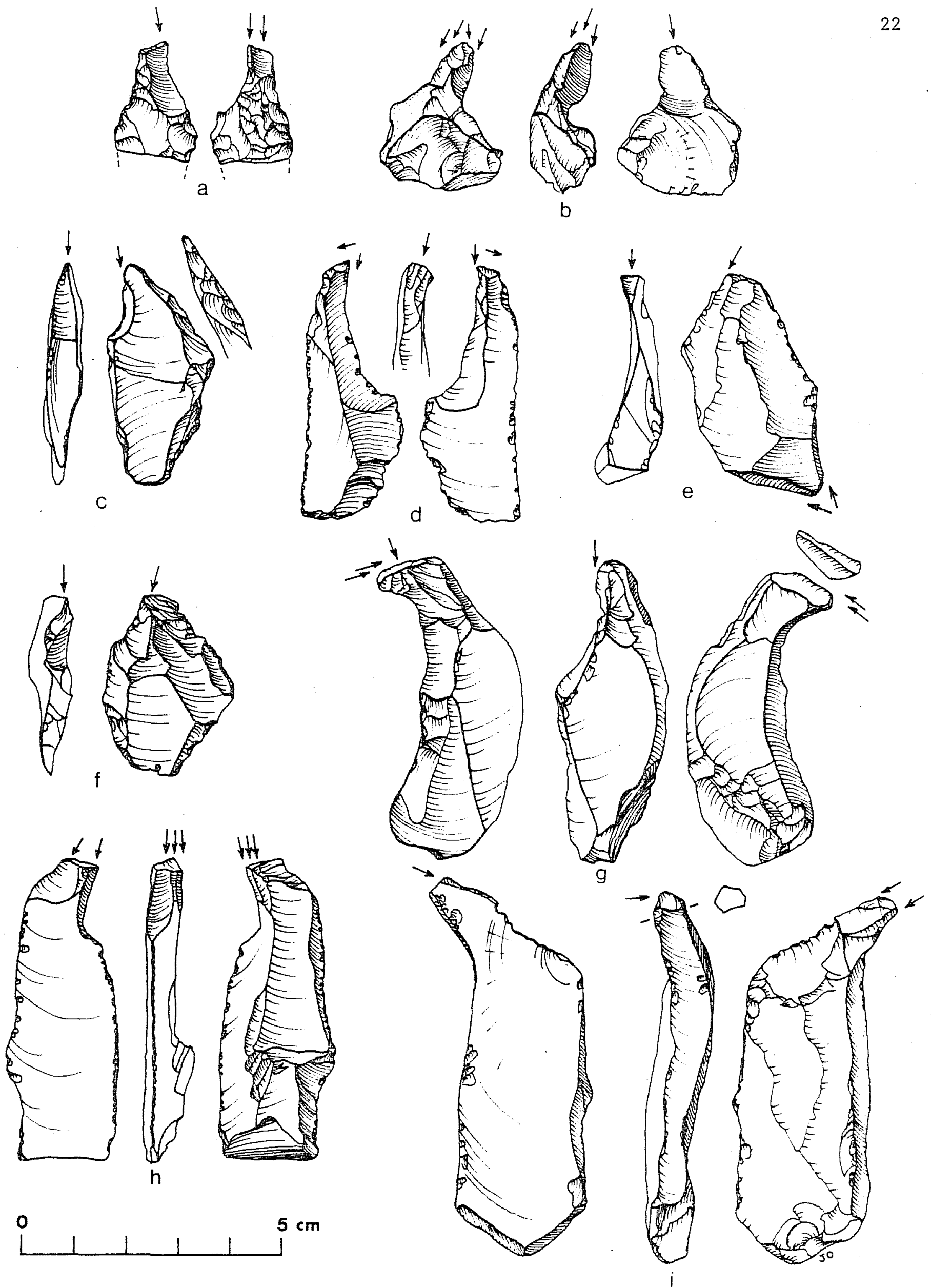


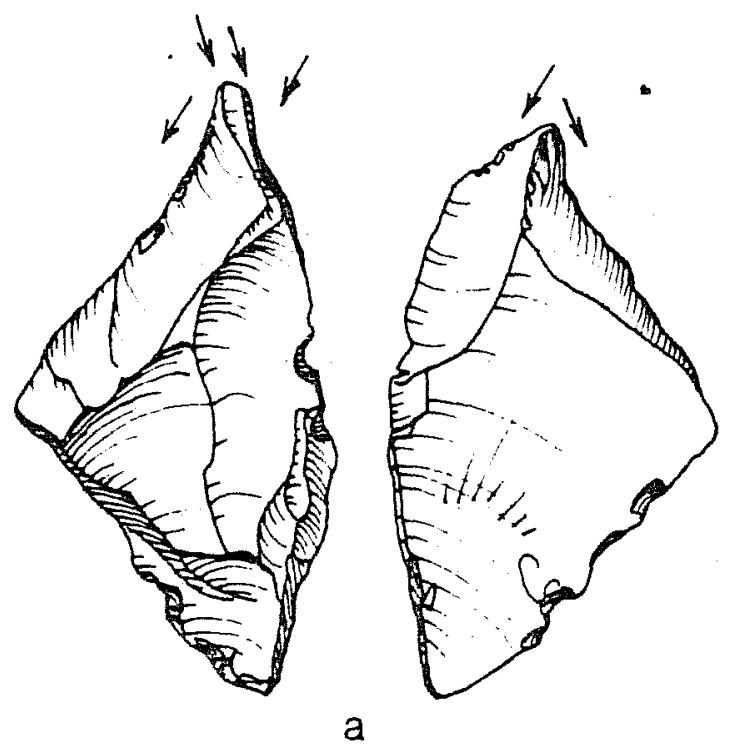

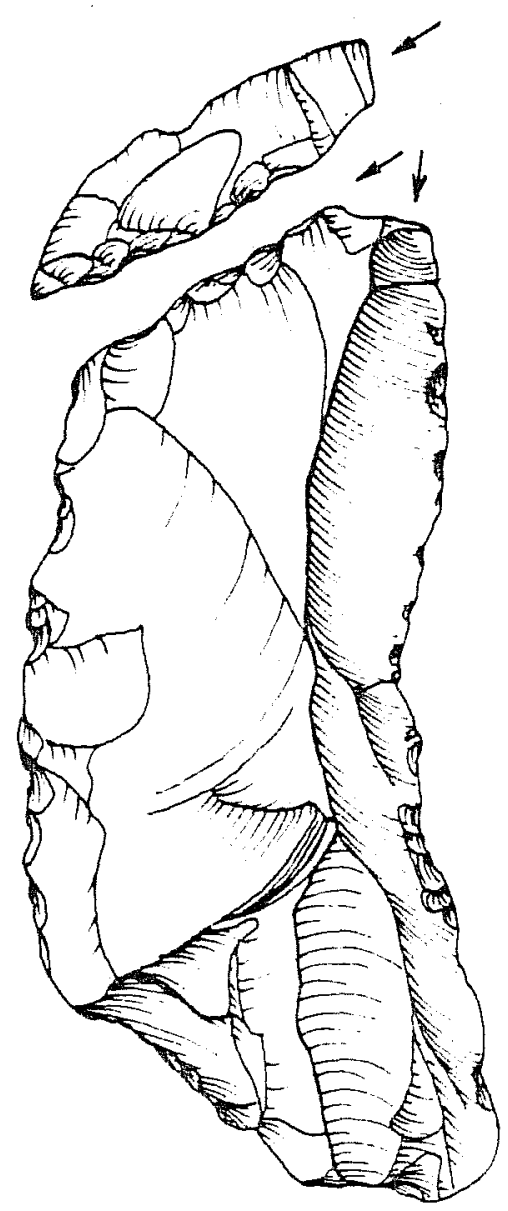

b
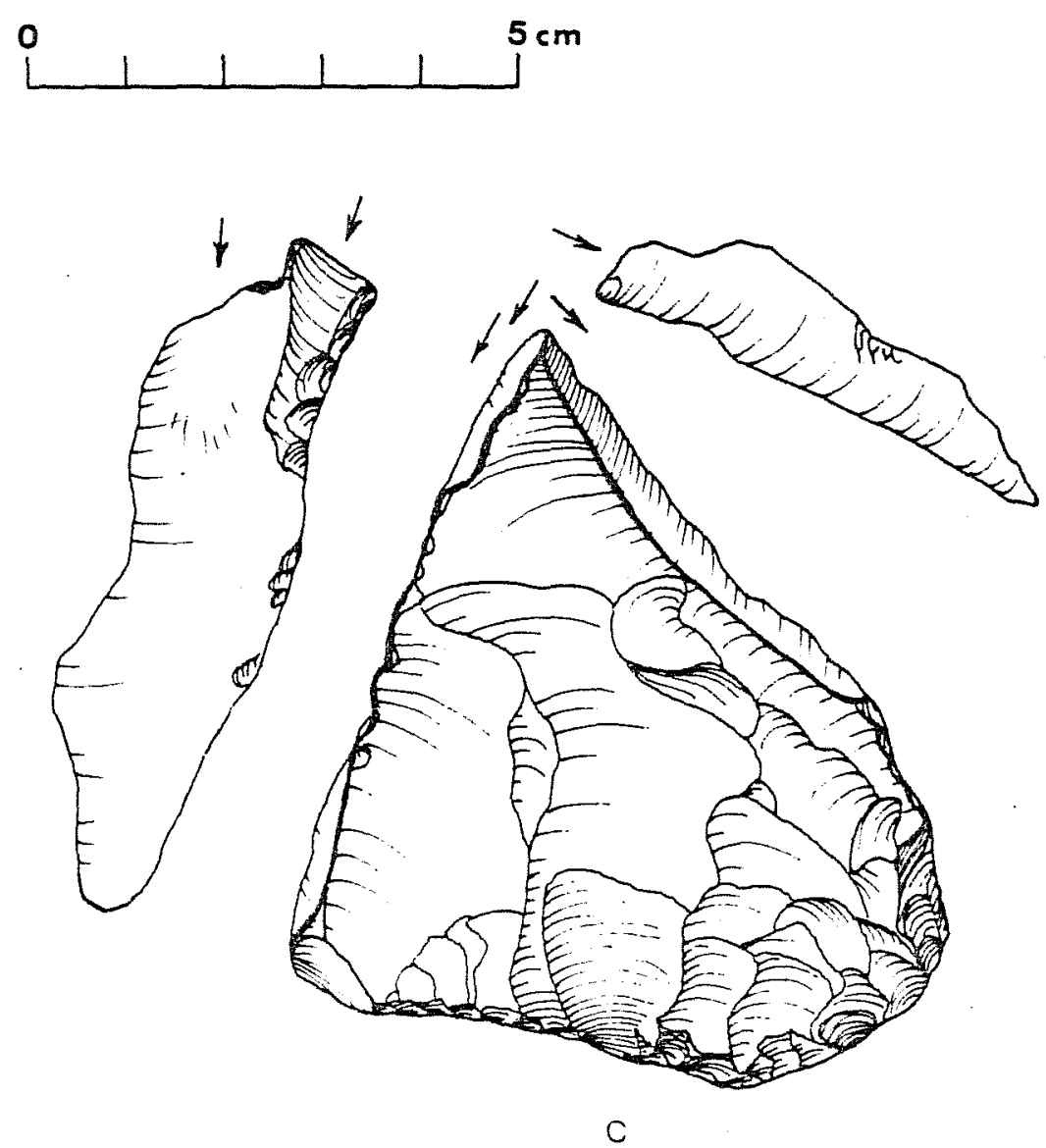


\section{REFERENCES CITED}

In addition to the usual bibliographical information, I have provided the addresses where several particularly relevant monographs may be ordered.

Alexander, Herbert L, Jr.

1963 The Levi Site: A Paleo-Indian Campsite in Central Texas. American Antiquity 28(4):510-528.

Bordaz, J.

1970 Tools of the OZd and New Stone Age. Natural History Press. Garden City, New York.

Bourlon, Lt. M.

1911 Essai de Classification of Burins, Leur Modes d'Avivage. Revue Anthropologique 21:267-278.

Burkitt, M. C.

1920 Classification of Burins or Gravers. Proceedings of the Prehistoric Society of East Anglia 3(2):306-310.

1963 The Ozd Stone Age. Atheneum, New York.

Clark, J. G. D. and M. W. Thompson

1954 The Groove and Splinter Technique of Working Antler in Upper Paleolithic and Mesolithic Europe, With Special Reference to the Material from Star Carr. Proceedings of the Prehistoric Society 19:146-160.

Coles, J. M. and E. S. Higgs

1969 The Archeology of Early Man. Faber and Faber, London.

Crabtree, Don E.

1972 An Introduction to Flintworking. Occasional Papers of the Idaho State Museum 28. Pocatello. (University Bookstore, Box 8013, Idaho State University, Pocatello, Idaho 83209.) 
Epstein, J. F.

1960 Burins From Texas. American Antiquity 26(1):93-97.

1963a The Burin Faceted Projectile Point. American Antiquity 29

(2) : 187-201.

1963b Centipede and Damp Caves. Excavations in Val Verde County, Texas, 1958. Bulletin of the Texas Archeological Society $33: 1-130$.

Giddings, J. L.

1956 The Burin Spal1 Artifact. Aretic 9(4):229-237.

1964 The Archeology of Cape Denbigh. Brown University Press, Providence.

Heizer, Robert F. and Harper Kelley

1961 Scraper Plane Burins. Southwest Museum Masterkey 35:146-150. Los Angeles.

Hester, Thomas R. and Robert F. Heizer

1973 Bibliography of Archaeology, I: Experiments, Lithic Technology, and Petrography. Addison-WesZey Module in Anthropology 29.

Movius, H. L., Jr.

1966 L'histoire de la Reconnaissance des Burins en Silex et de la Déscouverte de Leur Fonction en tant qu'Outils pendant le Paléolithique Supérieur. Bulzetin, Societé Prehistorique Francaise 63:50-65.

1968 Note on the History of the Discovery and Recognition of the Function of Burins as Tools. In: Vaufrey, Raymond, La Prehistorie, Problems et Tendences. Editions du Centre National de la Recherche Scientifique. Paris.

Movius, H. L., Jr., N. C. David, H. M. Bricker and R. B. Clay

1968 The Analysis of Certain Major Classes of Upper Paleolithic Tools. American School of Prehistoric Research. Peabody Museum, Harvard University, Buzletin 26.

Noone, H. V. V.

1934 A Classification of Flint Burins or Gravers. Journal of the Royal Anthropological Institute 64:81-92. 
Noone (continued)

1950 Notes on Flint Burins of the Vêzère (Dordogne) Sites. Proceedings of the Prehistoric Society 16:186-191.

1954 Burins of the Vézère Valley (Dordogne) Sites. Proceedings of the Prehistoric Society (for 1953) 19:116-120.

Oakley, R. P.

1964 Man, The Tool Maker. Phoenix Books. Chicago.

Pitzer, Jean M.

1977 Basic Sources for the Study of Burins. Archaeological Research Facility, Berkeley. (Department of Anthropology, University of California, Berkeley, California 94720.)

Pitzer, Jean M., T. R. Hester and R. F. Heizer

1974 Microblade Technology of the Channel Islands. Southwest Museum Masterkey 48:124-135.

Semenov, S. A.

1964 Prehistoric Technology. Translated by M. W. Thompson. Cory, Adams, and McKay, London.

Spencer, Lee

1974 Replicative Experiments in the Manufacture and Use of a Great Basin Atlatl. In: Hester, T. R., M. P. Mildner and L. Spencer. Great Basin Atlatl Studies. Ballena Press Publications in Archaeology, Ethnology, and History 2. Ramona.

Tixier, J.

1974 Glossary for the Description of Stone Tools, with Special Reference to the Epipaleolithic of the Maghreb. Newsletter of Lithic Technology, Special Publications 1. San Antonio. (Center for Archaeological Research, The University of Texas at San Antonio, San Antonio, Texas 78285.)

Tuohy, Donald R.

1969 Breakage, Burin Facets, and the Probable Technological Iinkage Among Lake Mohave, Silver Lake, and other Varieties of Paleoindian Projectile Points in the Desert West. Nevada State Museum Anthropological Papers 14. Carson City. 